\title{
Behavioral problems and tobacco use among adolescents in Central America and the Dominican Republic
}

\author{
Kenneth Vittetoe, ${ }^{1}$ Marsha F. Lopez, ${ }^{2}$ Jorge Delva, ${ }^{3}$ Fernando \\ Wagner, ${ }^{4}$ James $C$. Anthony, ${ }^{2}$ and the PACARDO research group ${ }^{5}$
}

ABSTRACT Objectives. The purpose of this study was to examine the association between behavioral problems and tobacco use among adolescent students in six countries of Central America and in the Dominican Republic.

Methods. Data were drawn from a multinational collaborative study that included questionnaire surveys of between 451 and 1170 school-attending adolescents in each of the seven countries studied. Assessments were based on an adapted, Spanish-language version of the Drug Use Screening Inventory (DUSI). The conditional form of logistic regression was employed for analysis, matching students on type of school and area, with further statistical adjustments for sex, age, and selected risk factors.

Results. Occurrence of tobacco use was observed to vary dramatically from country to country. Nonetheless, for the combined group of countries, the estimated odds of tobacco use in youths at the highest levels of behavioral problems was more than five times that for youths at the lowest levels, after controlling for sex, age, lack of participation in recreational activities, level of irritability, and levels of problems with school, family, and mental health. Countryspecific analyses show that youths at the highest levels of behavioral problems have a consistently greater occurrence of tobacco use as compared to youths at the lowest levels of behavioral problems.

Conclusions. These findings are concordant with prior studies on tobacco use among adolescents with behavioral problems. Although the magnitude of observed associations varied according to the country of residence, the strength of these associations and their significance by conventional standards were observed in nearly all the countries sampled. This is the first study in these seven countries on potentially causal relationships such as these. More research is needed to augment our knowledge regarding the observed cross-country differences and ultimately to develop, implement, and evaluate effective tobacco preventive intervention programs.

Key words Smoking, social behavior disorders, adolescents, Central America, Dominican Republic.

1 Hospital Psiquiátrico “Mario Mendoza," Departamento de Psiquiatría, Tegucigalpa, Honduras.

2 Johns Hopkins University, School of Hygiene and Public Health, Baltimore, Maryland 21205, United States of America. Send correspondence and reprint requests to: James C. Anthony, Johns Hopkins University, School of Hygiene and Public Health, 624 N. Broadway, 8th Floor, Baltimore, Maryland 21205, United States of America; telephone: 410-955-8551; fax: 410-955-9088; e-mail: janthony@jhu.edu
3 Florida State University, School of Social Work, Tallahassee, Florida, United States of America.

4 Instituto Nacional de Psiquiatría, División de Estudios Epidemiológicos y Sociales, Departamento de Investigaciones en Sistemas de Salud, Ciudad de México, México.

5 PACARDO stands for Panamá, Centro América, y República Dominicana. The PACARDO research group involves a multinational collaboration that rests on the efforts of many individuals, some of whom are listed below, by organization and coun- try: Organization of American States: Anna McG. Chisman, Luis Navarro Caris; Pan American Health Organization: Enrique Madrigal (retired); Costa Rica: Fernando Martínez Jiménez, Luis Sandí, Julio Bejarano; El Salvador: Ulises Gutiérrez, Juan Alfaro; Guatemala: Rodolfo Kepfer, Guillermo Meneses (deceased), Jorge Bolívar Díaz; Honduras: Kenneth Vittetoe, Felix Barahona; Nicaragua: Guillermo Gosebruch, Mauricio Sánchez; Panama: Gonzalo B. González, Miguel A. Cedeño, Marcel Penna; Dominican Republic: Manuel Herrera, Julia Hasbún. 
The Inter-American Drug Abuse Control Commission (IADACC) was organized as part of the work of the Organization of American States (OAS) in the early 1990s in response to reports documenting increasing use of tobacco, alcohol, and other drugs as well as a number of resultant health and social problems (1). With technical assistance from the Pan American Health Organization (PAHO), the IADACC participants developed an epidemiological surveillance drug-tracking system in Central America and the Dominican Republic that was intended to gather data from patients admitted to emergency rooms and drug treatment programs, from adults and youths incarcerated in detention centers, and from school-attending youth.

In this report we explore and estimate the strength of a potentially causal association between behavioral problems and tobacco use among youths attending schools in six countries of Central America-Costa Rica, El Salvador, Guatemala, Honduras, Nicaragua, and Panama-plus the Dominican Republic. Prior research has documented a significant positive association between tobacco use and behavioral problems, that is, behaviors that are detrimental to youth development, including fighting, swearing, and doing dangerous things (2-4). This association is evidenced by adolescents with a high degree of behavioral problems exhibiting more than twice the levels of smoking observed in youths with minimal behavioral problems, independent of exogenous variables such as disturbances of mood and attention. Furthermore, an increased occurrence of tobacco dependence has been observed in adolescents who have a history of early behavioral problems as compared to similar youth without such problems (5-7). This positive association appears to be valid cross-culturally, although data from Latin America are scanty $(2,3,5)$.

Behavioral problems have been associated with numerous other difficulties, including family and school troubles, social anxiety, and sleep and weight disturbances. In turn, all of these problems have been associated with tobacco use $(2,8)$. This observation suggests that there might be a network of interconnections among behavioral problems and tobacco use, with linkages to other difficulties.

In light of findings such as these, for this study we analyzed epidemiological surveillance data from the seven participating countries mentioned earlier to estimate the association between behavioral problems and tobacco use, attempting to control for some of the potential factors that might distort the association.

\section{MATERIALS AND METHODS}

The data we investigated were collected from samples surveyed in 1994 from the above-mentioned six Central American countries and from the Dominican Republic. The sample size in the seven nations ranged from 451 to 1170 students, who were aged 12-19 years and who were recruited as volunteer participants in the survey. Selected characteristics of the survey respondents are given in Table 1, displayed by country in order of estimated occurrence of tobacco smoking.

Anonymous self-report questionnaires were administered to these students in each classroom by trained survey staff members who introduced the project and answered questions before starting the assessment. The questionnaire was an adapted, Spanishlanguage version of the Drug Use Screening Inventory (DUSI). The DUSI was originally developed to assess alcohol and other drug use, school adjustment, and behavioral and psychological problems among youths in the United States of America, with questions designed to tap several interrelated problem domains thought to be associated with severity of drug involvement (9). Researchers from the participating countries translated and then back-translated the DUSI in order to have maximum language and conceptual equivalency. Although the original DUSI did not contain questions to ascertain tobacco use, ques- tions about lifetime and recent tobacco use were added to the Spanish version of the DUSI for use in this study. Although we assessed the use of other drugs, the frequency of reported use of such drugs as marijuana and cocaine was minimal in these schools, and thus we focused this analysis on tobacco.

The LISCOMP software package was used to examine and improve the psychometric properties of the DUSI scales via exploratory analyses using latent structure models for dichotomous data (10-11). The "behavioral problems" domain was measured well by the following six items, assessed using a dichotomous, Yes (1)—No (0) response format and whose total was summarized as a score ranging from 0 to 6 :

- Have you teased or done harmful things to animals?

- Do you swear or use dirty language a lot?

- Do you tease others a lot?

- Have you threatened to hurt people?

- Do you do risky or dangerous things a lot?

- Have you taken advantage of other people?

The country-specific internal consistency estimates for this behavioral problems scale ranged from 0.53 to 0.67 (Cronbach's alpha via KuderRichardson 20 formula for dichotomous items). This range is acceptable for a scale based on dichotomous items, but low enough to think that the study's estimates of the conducttobacco association might be attenuated. Six other domains were studied as covariates: associating with deviant peers, irritability, family attention, lack of participation in recreational activities, school problems, and mental health problems. The internal consistency estimates for these other domains were at about the same level or above the ones for the behavioral problems domain.

All analyses of gathered data were conducted with version 5.0 of the Stata statistical package (12). Initial exploratory analyses of the single-variable fre- 
TABLE 1. Selected demographic characteristics (in percentages) of the student samples, study of behavioral problems and tobacco use, Central America and the Dominican Republic, 1994

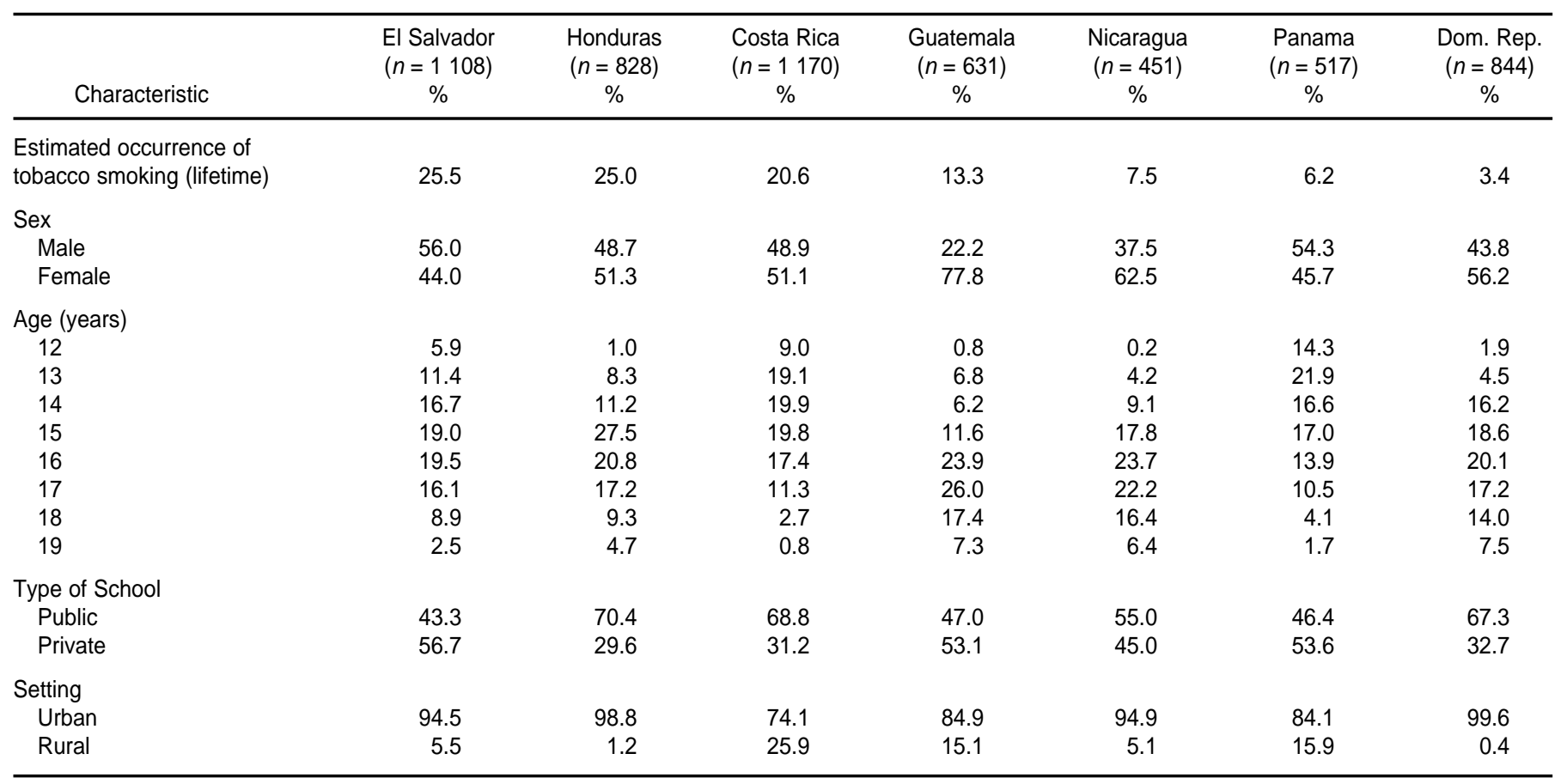

quency distributions showed that a large number of the student respondents received a score of zero because of the generally low occurrence of reported behavioral problems. In view of this skewness, three categories were formed. The first category represented students with the lowest level of behavioral problems (a score of 0 ), the second category represented students with a medium degree of behavioral problems (scores of 1 to 3 ), and the third category represented students with the highest level of behavioral problems (scores of 4 to 6). Estimates for the association involving tobacco use were obtained for the second and third categories, with the first category used as the reference.

To accommodate the multiregional and multischool structure of the sample, students were grouped into strata or risk sets defined by the school attended (public versus private) and the area where they were living at the time of sampling (urban versus rural). This poststratification or matching strategy holds constant the potentially confounding effects of unmeasured but commonly shared school and arealevel characteristics such as tobacco availability, advertisements, social disadvantage, and within-country district variations in enforcement of tobacco laws. As a result, all tobacco nonusers attending the same schools and living in the same areas as tobacco users serve as controls. This statistical method has been used extensively by our research group in prior studies of drug use in order to account for the potentially distorting influences of unmeasured neighborhood characteristics (for example, see 13-15).

In keeping with the poststratification approach, the conditional form of multiple logistic regression was used to assess the association between level of behavioral problems and occurrence of tobacco use. The model then was extended to include statistical adjustment for the hypothesized influ- ences of sex, age, and the other suspected covariates.

In the conditional logistic regression model, the occurrence of an event, in this case the odds of tobacco use, is estimated as a function of the suspected causal influence and covariates as in standard multiple logistic regression models, but with an allowance for a separate intercept for each matched risk set or strata as defined by the school students attended (public versus private) and by the area where they lived (urban versus rural). These analyses were conducted for all the studied countries as a whole and separately for each nation. We also explored possible interactions of behavioral problems with the variables of sex and age as a check on the validity of adjustments for these characteristics. After examination of the ratio of the estimated interaction coefficient and its standard error as well as the likelihood ratio test, we found no statistically significant interaction among these vari- 
ables. That is, adding these interaction terms did not result in an improved fit to any of the models tested $(P>0.10$; data not shown in a table).

\section{RESULTS}

The countries where we found the greatest proportion of students with a lifetime history of tobacco use were El Salvador, Honduras, Costa Rica, and Guatemala, and the countries with the lowest proportion of students with a lifetime history of tobacco use were Nicaragua, Panama, and the Dominican Republic (Table 1). Table 2 shows the results of the unadjusted and adjusted conditional logistic regression analyses for the seven countries together, and for each nation individually. With respect to the target hypothesis about behavioral problems, there was an overall positive association found between the presence of behavioral problems and occurrence of to- bacco use among students across the seven countries. Specifically, tobacco use was an estimated 2.9 times as likely to occur among students with moderate behavioral problems, and it was 8.9 times as likely to occur among students with severe behavioral problems, as compared to students with none of these problems (unadjusted relative odds for the moderate level of behavioral problems, $P<0.005$; for the high level of behavioral problems, $P<0.0005)$. The association between

TABLE 2. Estimated association (odds ratio and $95 \%$ confidence interval) between levels of behavioral problems and occurrence of tobacco use, according to results of conditional regression analyses, Central America and the Dominican Republic, 1994

\begin{tabular}{|c|c|c|c|c|c|}
\hline $\begin{array}{l}\text { Country/Level of } \\
\text { behavioral problems }\end{array}$ & $\begin{array}{l}\text { Initial model, } \\
\text { OR }(95 \% \mathrm{Cl})\end{array}$ & $\begin{array}{l}\text { Adjusted for sex, } \\
\text { OR }(95 \% \mathrm{Cl})\end{array}$ & $\begin{array}{l}\text { Adjusted for } \\
\text { sex \& age, } \\
\text { OR }(95 \% \mathrm{Cl})\end{array}$ & $\begin{array}{l}\text { Adjusted for sex, age } \\
\text { and some risk factors, }{ }^{a} \\
\text { OR }(95 \% \mathrm{Cl})\end{array}$ & $\begin{array}{l}\text { Adjusted for sex, age } \\
\text { and all risk factors, } \\
\text { OR }(95 \% \mathrm{Cl})\end{array}$ \\
\hline \multicolumn{6}{|l|}{ All seven countries } \\
\hline Low & 1.00 & 1.00 & 1.00 & 1.00 & 1.00 \\
\hline Medium & $2.93(2.38,3.61)$ & $2.80(2.27,3.45)$ & $2.82(2.28,3.48)$ & $2.34(1.88,2.90)$ & $2.25(1.81,2.81)$ \\
\hline High & $8.92(6.87,11.60)$ & $8.10(6.21,10.56)$ & $8.33(6.37,10.87)$ & $5.56(4.18,7.41)$ & $5.13(3.82,6.87)$ \\
\hline \multicolumn{6}{|l|}{ Costa Rica } \\
\hline Medium & $2.25(1.56,3.24)$ & $2.32(1.61,3.34)$ & $2.28(1.57,3.29)$ & $1.94(1.33,2.84)$ & $1.83(1.24,2.69)$ \\
\hline High & $6.70(4.05,11.11)$ & $7.44(4.42,12.52)$ & $7.48(4.43,12.64)$ & $4.53(2.56,8.01)$ & $3.82(2.10,6.94)$ \\
\hline \multicolumn{6}{|l|}{ Dominican Republic } \\
\hline Low & 1.00 & 1.00 & 1.00 & 1.00 & 1.00 \\
\hline Medium & $3.39(0.76,15.06)$ & $3.12(0.70,13.94)$ & $3.07(0.69,13.71)$ & $2.96(0.63,13.78)$ & $2.27(0.47,10.96)$ \\
\hline High & $15.51(3.24,74.26)$ & $10.21(2.06,50.54)$ & $9.77(1.97,48.46)$ & $8.50(1.53,47.17)$ & $6.73(1.18,38.35)$ \\
\hline \multicolumn{6}{|l|}{ El Salvador } \\
\hline \multicolumn{6}{|l|}{ Guatemala } \\
\hline Low & 1.00 & 1.00 & 1.00 & 1.00 & 1.00 \\
\hline Medium & $1.69(0.97,2.95)$ & $1.66(0.94,2.96)$ & $1.66(0.94,2.97)$ & $1.25(0.68,2.29)$ & $1.19(0.63,2.23)$ \\
\hline High & $4.82(2.12,10.96)$ & $4.88(2.03,11.70)$ & $4.91(2.04,11.80)$ & $2.92(1.15,7.40)$ & $2.28(0.86,6.02)$ \\
\hline \multicolumn{6}{|l|}{ Honduras } \\
\hline Low & 1.00 & 1.00 & 1.00 & 1.00 & 1.00 \\
\hline Medium & $3.77(2.37,6.00)$ & $3.64(2.28,5.81)$ & $3.56(2.23,5.69)$ & $3.02(1.86,4.91)$ & $3.20(1.95,5.26)$ \\
\hline High & $10.08(5.62,18.09)$ & $9.44(5.23,17.07)$ & $9.25(5.11,16.75)$ & $6.91(3.68,12.98)$ & $6.99(3.67,13.31)$ \\
\hline \multicolumn{6}{|l|}{ Nicaragua } \\
\hline Low & 1.00 & 1.00 & 1.00 & 1.00 & 1.00 \\
\hline Medium & $3.27(1.31,8.18)$ & $3.22(1.28,8.10)$ & $3.17(1.26,7.99)$ & $2.61(1.00,6.77)$ & $2.66(1.01,7.04)$ \\
\hline High & $6.65(1.69,26.18)$ & $6.41(1.60,25.75)$ & $6.41(1.59,25.79)$ & $4.09(0.92,18.18)$ & $3.53(0.75,16.70)$ \\
\hline
\end{tabular}

\footnotetext{
${ }^{a}$ Adjusted for sex, age, and the following risk factors: irritability and association with deviant peers.

${ }^{\mathrm{b}}$ Adjusted for sex, age, and the following risk factors: association with deviant peers, irritability, family attention, lack of participation in recreational activities, school problems, and mental health problems.
} 
behavioral problems and tobacco use decreased somewhat after adjustments for sex, age, and the aforementioned six covariates (e.g., deviant peers, irritability, family attention, lack of participation in recreational activities, school problems, mental health problems) but retained strength.

The bivariate analyses for each country showed a positive association between behavioral problems and tobacco use in all the countries studied, with odds of tobacco use increasing with the level of behavioral problems (Table 2). In fact, the odds of tobacco use for severe behavioral problems is more than double the odds for moderate behavioral problems in all the countries under the unadjusted model, as shown in the first column of Table 2. In Costa Rica the occurrence of tobacco use was an estimated 6.7 times as high for youths with the higher levels of behavioral problems as compared to youths in the reference category $(P<0.0005)$. In Guatemala the occurrence of tobacco use was an estimated 4.8 times as high for youths at the high levels of behavioral problems as compared to youths at the lowest levels of problems $(P<0.0005)$. In El Salvador, the occurrence of tobacco use was an estimated 12.1 times as high for youths at the high levels of behavioral problems as compared to youths at the lowest levels $(P<0.001)$. The fully adjusted estimates (shown in the last column in Table 2) indicate a slight decrease in the strength of the associations. With the exception of Guatemala and Nicaragua, these associations remained significant when tobacco use was compared between the highest and lowest levels of behavioral problems.

\section{DISCUSSION}

The main finding of this research is that there is a moderate-to-strong association between levels of behavioral problems and occurrence of tobacco use among the youths sampled for the seven participating countries as a whole, and for each participating nation. Except in Guatemala and Nica- ragua, all the observed associations remained moderate-to-strong in magnitude once adjustments for sex, age, and other risk factors were made.

Several limitations of this study should be mentioned prior to discussing the study findings. The crosssectional nature of the study does not allow us to make causal inferences about the association between behavioral problems and occurrence of tobacco use. Prospective or experimental studies of school-age youths are more appropriate to test the temporal and causal associations between behavioral problems and tobacco use, although one might suspect that behavioral problems predate the tobacco use reported in this study. Additionally, the generalizability of the findings is somewhat affected because the samples were not drawn to be representative of the population of youths in each country. Finally, differences in sample size might have introduced survey errors. Response biases associated with socially desirable reporting and other errors in recognition or recall might bias the results.

Notwithstanding limitations such as these, ours is the first study to examine the suspected causal association between behavioral problems and tobacco use in the seven countries. The study's strengths include use of an epidemiological matching strategy (poststratification) and the conditional logistic regression model, in an attempt to control for factors that might otherwise confound or distort our estimates of the observed association.

The findings of this study indicate an intriguing positive association between levels of behavioral problems and occurrence of tobacco use. These associations remain after adjustment for the potential distorting influences of sex, age, and alternative suspected influences on tobacco use, with the exception of two countries, Guatemala and Nicaragua. In Guatemala the odds ratios comparing the highest and medium levels of behavioral problems to those without behavioral problems were no longer significant when adjustments for all covariates were made.
In Nicaragua the odds ratio comparing the highest and the lowest levels of behavioral problems was no longer significant after adjusting for all covariates. Given the available data, it is impossible to identify the specific reasons for these differences in odds ratios for youths in the Guatemala and Nicaragua samples. One possibility is that demographic differences or differences in other risk factors accounted for the loss of significance observed in the fully adjusted models in these two countries. Additional country-specific and comparative studies are necessary to clarify these differences.

These findings highlight three important issues. First, the observed prevalence of tobacco use among youths in the participating countries has yet to be addressed, and it remains a serious public health problem. Student tobacco use merits concern in view of studies that have demonstrated an association between early tobacco use and later use of other drugs (e.g., marijuana) and other risky behaviors (16-19) as well as cancer and other serious health consequences (20). The importance of this problem is further magnified for young smokers, whose early involvement with tobacco may place them even more prematurely on the path toward damaging outcomes.

A second issue is the lack of knowledge available regarding the mechanisms by which youths initiate and maintain tobacco use. A direct causal association between behavioral problems and tobacco use has yet to be confirmed, and the presence of distorting influences may play a part in the apparent causality (21).

The above issue leads us to a final observation: There is reason to examine not only the mechanisms by which tobacco use begins and is maintained, but also how these mechanisms vary within and across cultures and countries. As the data in this study indicate, prevalence proportions and odds ratios measuring the associations between behavioral problems and tobacco use vary somewhat from one country to another. 
We hope that studies such as this one can generate more interest in studying the public health problems associated with youth tobacco smoking in these seven countries. As a result of this study, funding from the National Institute on Drug Abuse (NIDA) of the United States of America was obtained in the late 1990s to conduct additional school-based surveys of drug use in the same countries that participated in this study. With the funding provided by NIDA, in 1999 investigators from these seven participating countries formed a working group called PACARDO (Panamá, Centro América, y República Dominicana) to conduct a representative national survey of drug use among schoolattending youths in their corresponding countries. Data collection for this project has ended. We hope to present these new findings and comparisons with the results of the 1994 surveys in subsequent publications. It is our hope that findings such as those presented in this study and the ones to be generated by the PACARDO group can serve as a guide in the efforts to allocate resources to facilitate the development, implementation, and evaluation of effective tobacco preventive intervention programs targeted towards the young population in these nations.
Acknowledgments. Data-gathering for this article was supported with matching funds from each participating country and grants-in-aid or organizational support from various institutions in the United States of America as well as from the Organization of American States and the Pan American Health Organization. This work provided preliminary data to obtain funding from the National Institute on Drug Abuse (RO1 DA10502) to conduct additional surveys of drug use among school-attending populations in these seven countries in the late 1990s.

\section{REFERENCES}

1. Organization of American States. Inter-American Drug Abuse Control Commission [Internet site]. Available at: http://www.cicad.oas. org/en/Main/main.htm. Accessed 6 February 2002.

2. Calafat A, Amengual M, Palmer A, Saliba C. Drug use and its relationship to other behavior disorders and maladjustment signs among adolescents. Subst Use Misuse 1997;32:1-24

3. Lynskey MT, Fergusson DM. Childhood conduct problems, attention deficit behaviors, and adolescent alcohol, tobacco, and illicit drug use. J Abnorm Psychol 1995;23:281-302.

4. Miller-Johnson S, Lochman JE, Coie JD, Terry $\mathrm{R}$, Hyman C. Comorbidity of conduct and depressive problems at sixth grade: substance use outcomes across adolescence. J Abnorm Child Psychol 1998;26:221-232.

5. Reif CJ, Elster AB. Adolescent preventive services. Prim Care 1998;25:1-21.

6. Kellam SG, Brown CH, Rubin BR, Ensminger ME. Paths leading to teenage psychiatric symptoms and substance use: developmental epidemiological studies in Woodlawn. In: Guze SB, Earls FJ, Barrett JE, eds. Childhood psychopathology and development. New York, New York: Raven Press; 1983. Pp. 17-55.

7. Bardone AM, Moffitt TE, Caspi A, Dickson N, Stanton WR, Silva PA. Adult physical health outcomes of adolescent girls with conduct disorder, depression, and anxiety. J Am Acad Child Adolesc Psychiatry 1998;37:594-601.

8. Sonntag H, Wittchen HU, Hofler M, Kessler $\mathrm{RC}$, Stein MB. Are social fears and DSM-IV so84(11):1825-1827. cial anxiety disorder associated with smoking and nicotine dependence in adolescents and young adults? Eur Psychiatry 2000;15:67-74.

9. Tarter RE, Hegedus AM. The Drug Use Screening Inventory: its applications in the evaluation and treatment of alcohol and other drug abuse. Alcohol Health Res World 1991; 15(1):65-75.

10. Muthén B. LISCOMP [software program]. Chicago, Illinois, United States of America: Scientific Software International; 1987.

11. Muthén B. LISCOMP. Analysis of linear structural relations using a comprehensive measurement model. A program for advanced research [software manual]. Los Angeles, California, United States: University of California at Los Angeles; 1989.

12. Stata Corporation. Stata 5.0 statistics/data analysis. College Station, Texas, United States: Stata Corporation; 1996.

13. Wagner-Echeagaray FA, Schütz CG, Chilcoat HD, Anthony JC. Degree of acculturation and risk of crack-cocaine smoking among Hispanic Americans. Am J Public Health 1994;

14. Neumark YD, Delva J, Anthony JC. The epidemiology of adolescent inhalant drug involvement. Arch Pediatr Adolesc Med 1998; 152(8):781-786.

15. Delva J, Furr CDM, Anthony JC. Personal characteristics associated with injecting-drug use among Latinas in the United States of America. Rev Panam Salud Publica 1998;4(5): 341-345.
16. Kandel DB, Yamaguchi K, Chen K. Stages of progression in drug involvement from adolescent to adulthood: further evidence for the gateway theory. J Stud Alcohol 1992;53(5): 447-457.

17. Coogan PF, Geller A, Adams M. Prevalence and correlates of smokeless tobacco use in a sample of Connecticut students. J Adolesc 2000;23:129-135.

18. Jarvick ME, Schneider NG. Nicotine. In: Lowinson JH, Ruiz P, Millman RB, eds. Substance abuse: a comprehensive textbook. Baltimore, Maryland, United States: Williams \& Wilkins; 1992. Pp. 334-356.

19. Ary DV, Duncan TE, Biglan A, Metzler CW, Noell JW, Smolkowski K. Development of adolescent problem behavior. J Abnorm Child Psychol 1999;27:141-150.

20. United States, Department of Health and Human Services. Reducing the health consequences of smoking: 25 years of progress. A report of the Surgeon General. Washington, D.C.: Government Printing Office; 1989.

21. Kellam SG, Anthony JC. Targeting early antecedents to prevent tobacco smoking: findings from an epidemiologically based randomized field trial. Am J Public Health 1998; 88(10):1490-1495.

Manuscript received 26 October 2000. Revised version accepted for publication 28 December 2001. 
RESUMEN Objetivos. Investigar la asociación entre los problemas conductuales y el consumo de tabaco en estudiantes adolescentes de seis países centroamericanos y la República Dominicana.

\section{Problemas conductuales y consumo de tabaco en adolescentes de Centroamérica y la República Dominicana}

Métodos. Los datos fueron extraídos de un estudio internacional en el que, en cada país, se aplicaron cuestionarios a 451-1 170 estudiantes adolescentes. Las evaluaciones se basaron en una versión adaptada al español del Cuestionario de Tamizaje del Consumo de Drogas (Drug Use Screening Inventory). Los análisis se realizaron mediante regresión logística condicional; los estudiantes se aparearon según el tipo de escuela y la zona, y se efectuaron otros ajustes estadísticos en función del sexo, edad $\mathrm{y}$ algunos factores de riesgo.

Resultados. El consumo de tabaco presentó enormes variaciones de un país a otro. No obstante, combinando los datos de todos los países y controlando los efectos del sexo, edad, falta de participación en actividades recreativas, grado de irritabilidad y magnitud de los problemas escolares, familiares y de salud mental, se estimó que el consumo de tabaco en los jóvenes con los mayores grados de problemas conductuales era más de cinco veces mayor que en los jóvenes con los menores grados de problemas conductuales. Los análisis de cada país revelaron que los jóvenes con mayores problemas conductuales presentaban constantemente mayor consumo de tabaco que los jóvenes con menores problemas conductuales.

Conclusiones. Estos resultados concuerdan con los de estudios anteriores acerca del consumo de tabaco en adolescentes con problemas conductuales. Aunque su magnitud varió en función del país de residencia, las asociaciones observadas fueron fuertes y significativas según los criterios convencionales en casi todos los países estudiados. Este es el primer estudio que se realiza en estos siete países para investigar posibles relaciones causales como estas. Son necesarias más investigaciones para ampliar los conocimientos sobre las diferencias observadas entre los distintos países y, en definitiva, para crear, poner en práctica y evaluar programas eficaces de intervención preventiva contra el consumo de tabaco.

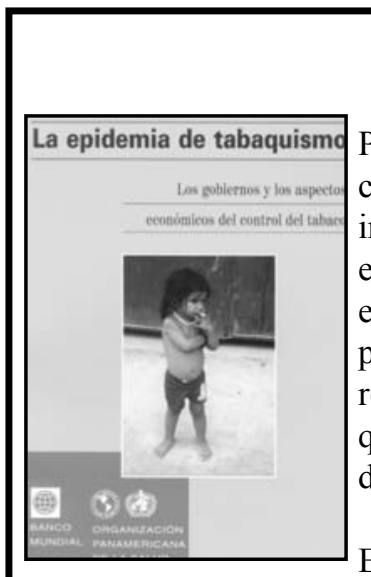

\section{La epidemia de tabaquismo: los gobiernos y los aspectos económicos del control del tabaco}

2000, 133 pp., ISBN 9275315779 Código: PC 562, Precio: US\$25.00/ US\$ 18.00 en América Latina y el Caribe
Por primera vez se ofrece una evaluación actualizada de los aspectos económicos del control del tabaco en un informe sencillo y conciso, en el que se revisa la experiencia internacional. Las conclusiones del informe son que la elevación de los impuestos sobre el tabaco puede salvar millones de vidas y aumentar, al mismo tiempo, los ingresos estatales a mediano plazo, y que otras medidas no relacionadas con el precio, como la prohibición completa de la publicidad y de la promoción de los cigarrillos, también reducirían de forma significativa el consumo de tabaco. El análisis examina los efectos que las políticas de control del tabaco tienen sobre el empleo y se llega a la conclusión de que la mayoría de los países no sufrirían pérdidas permanentes de puestos de trabajo.

El informe examina también los costos de las políticas de control y establece un calendario para la acción de los gobiernos, incluida la ayuda a los cultivadores de tabaco más pobres. Señala asimismo el papel que deben desempeñar los organismos internacionales en la reducción de la carga evitable de muertes prematuras y discapacidades relacionadas con el tabaco.

http://publications.paho.org • Fax: (301) 206-9789 • Correo electrónico:paho@pmds.com 